\title{
Therapeutic impact of human serum albumin-thioredoxin fusion protein on influenza virus-induced lung injury mice
}

\section{Ryota Tanaka ${ }^{1 \dagger}$, Yu Ishima ${ }^{1,2+}$, Yuki Enoki ${ }^{1}$, Kazuhiko Kimachi ${ }^{3}$, Tatsuya Shirai ${ }^{3}$, Hiroshi Watanabe ${ }^{1,2}$, Victor T. G. Chuang ${ }^{4}$, Toru Maruyama ${ }^{1,2 *}$ and Masaki Otagiri ${ }^{5,6 *}$}

\author{
' Department of Biopharmaceutics, Graduate School of Pharmaceutical Sciences, Kumamoto University, Kumamoto, Japan \\ ${ }^{2}$ Center for Clinical Pharmaceutical Sciences, School of Pharmacy, Kumamoto University, Kumamoto, Japan \\ ${ }^{3}$ The Chemo-Sero-Therapeutic Research Institute (KAKETSUKEN), Kumamoto, Japan \\ ${ }^{4}$ Curtin Health Innovation Research Institute, School of Pharmacy, Faculty of Health Sciences, Curtin University, Perth, WA, Australia \\ ${ }^{5}$ Faculty of Pharmaceutical Sciences, Sojo University, Kumamoto, Japan \\ ${ }^{6}$ DDS Research Institute, Sojo University, Kumamoto, Japan
}

\section{Edited by:}

Jan Terje Andersen, Oslo University Hospital, Norway

\section{Reviewed by:}

Peter Timmerman, Pepscan

Therapeutics B.V., Netherlands

Daniel Olive, Institut national de la

santé et de la recherche médicale,

France

*Correspondence:

Toru Maruyama, Department of

Biopharmaceutics, Graduate School

of Pharmaceutical Sciences,

Kumamoto University, 5-1

Oe-honmachi, Kumamoto 862-0973,

Japan

e-mail: tomaru@gpo.kumamoto-

u.ac.jp;

Masaki Otagiri, Faculty of

Pharmaceutical Sciences, Sojo

University, 4-22-1 Ikeda, Kumamoto

860-0822, Japan

e-mail: otagirim@ph.sojo-u.ac.jp

${ }^{\dagger}$ Ryota Tanaka and Yu Ishima have contributed equally to this work.
Reactive oxygen species (ROS) are the primary pathogenic molecules produced in viral lung infections. We previously reported on the use of a recombinant human serum albumin (HSA)-thioredoxin 1 ( $T r x$ ) fusion protein (HSA-Trx) for extending the half-life $\operatorname{Tr} x$, an endogenous protein with anti-oxidant properties. As a result, it was possible to overcome the unfavorable pharmacokinetic and short pharmacological properties of Trx. We hypothesized that HSA-Trx would attenuate the enhanced ROS production of species such as hydroxyl radicals by neutrophils during an influenza viral infection. The levels of 8-hydroxy2'-deoxyguanosine and 3-nitrotyrosine were used as indices of the anti-oxidant activity of HSA-Trx. In addition, the cytoprotective effects of HSA-Trx were examined in PR8 (H1N1) influenza virus-induced lung injured mice. The findings show that HSA-Trx reduced the number of total cells, neutrophils, and total protein in BALF of influenza virus-induced lung injured mice. The HSA-Trx treatment significantly decreased the level of 8-hydroxy2'-deoxyguanosine and 3-nitrotyrosine, but failed to inhibit inducible nitric oxide synthase expression, in the lungs of the virus-infected mice. On the other hand, Tamiflu ${ }^{\circledR}$ treatment also significantly suppressed the production of inflammatory cells and neutrophil infiltration, as well as the protein level in BALF and lung histopathological alterations caused by the influenza virus. The suppressive effect of Tamiflu ${ }^{\circledR}$ was slightly stronger than that of HSA-Trx. Interestingly, Tamiflu ${ }^{\circledR}$ significantly decreased virus proliferation, while HSA-Trx had no effect. These results indicate that HSA-Trx may be of therapeutic value for the treatment of various acute inflammatory disorders such as influenza-virus-induced pneumonia, by inhibiting inflammatory-cell responses and suppressing the overproduction of NO in the lung.

\section{Keywords: albumin, thioredoxin, fusion, anti-oxidization, influenza virus}

\section{INTRODUCTION}

Influenza virus infections cause a broad array of illnesses, including acute lung injuries (ALI), which are responsible for vital morbidity and mortality both in children and adults (1). Although most influenza A viruses cause a transitory localized debilitating respiratory illness in human beings, more severe respiratory and systemic complications that are sometimes fatal can arise, as evidenced by the pandemic influenza of 1918 caused by the H1N1 virus and the highly pathogenic avian H5N1 virus (2). In addition, the novel swine-origin influenza virus H1N1 that spread globally in 2009 was an attenuated strain, but children and patients with a pre-existing disease developed more severe infections (3).

There are several, currently available antiviral therapeutic agents, including neuraminidase inhibitors, oseltamivir (Tamiful $^{\circledR}$ ) and zanamivir (Relenza ${ }^{\circledR}$ ) to combat seasonal and pandemic influenza A virus outbreaks (4). These antiviral agents that prevent the release of the influenza virus from already infected cells and the transmission of the virus are clearly effective in the treatment of such infections. However, emerging evidence suggests that certain strains of the influenza virus are developing resistance to these antivirals, and sometimes cause severe ALI, requiring intensive care and mechanical ventilation in clinical settings (5). Therefore, the development of newer, more effective therapeutic approaches that differ from traditional virus based strategies is of great importance.

Recent studies have suggested that oxidative stress plays an important role in the pathogenesis and development of influenzainduced ALI (6). At the time of an influenza infection, several cells of the innate immune system, such as alveolar macrophages and neutrophils release reactive oxygen species (ROS) and reactive nitrogen species (RNOS), including as superoxide $\left(\mathrm{O}_{2}^{--}\right)$, hydroxyl radical $(\cdot \mathrm{OH})$, nitric oxide $(\mathrm{NO})$, and peroxynitrite $\left(\mathrm{ONOO}^{-}\right)$ in order to combat the invading virus. However, the resulting overproduced ROS and RNOS not only exert a direct cytopathic effect on viral replication in the infected cells but also induced the 
apoptotic cell death of non-infected cells. That ROS and RNOS play critical roles as mediators of virus-induced lung damage is supported studies in which exogenous anti-oxidants, such as superoxide dismutase (SOD), catalase (anti-oxidative enzymes), allopurinol (xanthine oxidase inhibitor), or $N$-monomethyl-Larginine (NO synthase inhibitor) decreased the extent of lung damage and mortality in influenza-infected mice (7-9). In addition, the overexpression of extracellular SOD or heme oxygenase-1 was reported to suppress lung injury and inflammation, resulting in an improved survival rate $(10,11)$.

Thioredoxin-1 (Trx) is a small redox-active protein $(12 \mathrm{kDa})$ that is ubiquitously present in the human body and is one of the defense proteins that are induced in response to various oxidative stress conditions (12). In addition to its potent anti-oxidative effect, which is derived from dithiol-disulfide exchange in its active site, Trx also has anti-inflammatory properties, due mainly to its ability to inhibit neutrophil chemotaxis to inflammatory sites (13). Because of its desirable anti-oxidative and anti-inflammatory properties, Trx represents a new and potentially effective therapeutic agent for the treatment of influenza virus-induced ALI. However, since Trx is eliminated extensively via glomerular filtration, its plasma half-life is only about $1 \mathrm{~h}$ in mice and $2 \mathrm{~h}$ in rats, which is extremely short in terms of producing a significant therapeutic impact $(13,14)$. In order to obtain a satisfactory therapeutic outcome, a sustainable therapeutic concentration of Trx would be needed. To achieve this, a constant infusion or frequent repeated administrations of Trx would be required. In fact, Yashiro et al. reported that exogenous recombinant Trx was effective in inhibiting influenza virus-induced lung damage, when administered intraperitoneally 2 day intervals (15).

In an attempt to increase the blood retention time of Trx, we recently produced a genetically engineered fusion protein comprises human serum albumin (HSA) and Trx (HSA-Trx) using a Pichia expression system (16). The incentives for targeting albumin are that it constitutes the most abundant serum protein in blood, and albumin has an extraordinary long half-life of 23 weeks in human beings. In addition to having a molecular size above the renal clearance threshold, the long half-lives are attributed to the efficient receptor-mediated recycling pathway involving the neonatal $F_{c}$ receptor ( $\left.F c R n\right)$ (17). Actually, the plasma half-life of the HSA-Trx fusion protein in normal mice was found to be similar to that of HSA, which is 10 times longer than the plasma half-life of Trx itself. Interestingly, HSA-Trx showed a higher distribution in the lungs than $\operatorname{Trx}(16)$. Therefore, a further attempt will be made to investigate the clinical usefulness of HSA-Trx in treating oxidative stress and inflammation related lung disorders.

The purpose of this study was to investigate the therapeutic impact of HSA-Trx in the treatment of influenza-induced ALI. Using an influenza-induced ALI mouse model, the results showed that HSA-Trx could prevent this disease via its long acting anti-oxidative and anti-chemotaxis effects.

\section{MATERIALS AND METHODS \\ EXPERIMENTAL ANIMALS AND REAGENTS}

Sea-ICR mice ( 5 weeks, male) were obtained from Kyudo Co., Ltd. (Saga, Japan). Blue Sepharose 6 Fast Flow, HiTrap Phenyl HP column and PD-10 desalting column were obtained from GE
Healthcare (Tokyo, Japan). Chloral hydrate was obtained from Sigma (Tokyo, Japan). Diff-Quick reagents were purchased from Kokusai Shiyaku (Kobe, Japan). Coomassie Brilliant Blue solution and HistoVT One were obtained from Nacalai Tesque (Kyoto, Japan). Interferon- $\gamma($ IFN- $\gamma)$ ELISA kit was purchased from Biolegend (San Diego, CA, USA). Mayer's hematoxylin, a $1 \%$ eosin alcohol solution, mounting medium for histological examinations (malinol) were from Muto Pure Chemicals (Tokyo, Japan). 4',6Diamidino-2-phenylindole (DAPI) was obtained from Dojindo (Kumamoto, Japan). All other chemicals were of the highest analytical grades available.

\section{PRODUCTION OF HSA-TrX FUSION PROTEIN}

Human serum albumin, Trx, and the HSA-Trx fusion protein were produced following previously reported methods $(18,19)$. Transformed Pichia pastoris cells were incubated in $1250 \mathrm{ml}$ of BMGY liquid media [1\% yeast extract, $2 \%$ pepton, $100 \mathrm{mM}$ potassium phosphate $(\mathrm{pH} 6.0), 1.34 \%$ yeast nitrogen base with ammonium sulfate without amino acids, $4 \times 10^{-5} \%$ biotin, $1 \%$ glycerol] (growth phase) for 2 days $\left(\mathrm{OD}_{600}=2\right)$, and was then cultured in $800 \mathrm{ml}$ of BMMY media that contained a protein expression inducer as well as a carbon source, methanol [1\% yeast extract, $2 \%$ pepton, $100 \mathrm{mM}$ potassium phosphate ( $\mathrm{pH} 6.0$ ), $1.34 \%$ yeast nitrogen base with ammonium sulfate without amino acids, $4 \times 10^{-5} \%$ biotin, $1 \%$ methanol] (protein induction phase) for 3 days at $30^{\circ} \mathrm{C}$. Methanol was added at $12 \mathrm{~h}$ intervals to permit the concentration of methanol to be maintained at $1 \%$ in order to sustain the protein expression induction effect. Purification of the fusion protein was initially carried out by chromatography on a Blue Sepharose 6 Fast Flow column equilibrated with $200 \mathrm{mM}$ sodium acetate buffer ( $\mathrm{pH}$ 5.5) after dialysis against the same buffer. Using AKTA prime, a $5 \mathrm{ml}$ HiTrap Phenyl HP column for hydrophobic chromatography, the following conditions were employed: Buffer A, $50 \mathrm{mM}$ Tris- $\mathrm{HCl} / 1.5 \mathrm{M}$ ammonium sulfate, $\mathrm{pH}$ 7.0; Buffer B, 50 mM Tris- $\mathrm{HCl}, \mathrm{pH} 7.0$; Gradient, 0-100\% (Buffer B) $100 \mathrm{ml}$; Flow rate, $3 \mathrm{ml} / \mathrm{min}$. The fusion protein was analyzed by SDS-PAGE on a $10 \%$ polyacrylamide gel, with Coomassie blue R250 staining. The purity of the fusion protein was estimated to be in excess of $97 \%$.

\section{PRODUCTION OF INFLUENZA-INDUCED ALI MICE MODEL}

Influenza virus A/Puerto Rico/8/34 (H1N1) was used throughout the experiments. All animal experiments were conducted in accordance with the guidelines of Center for Animal Resources and Development, Kumamoto University for the care and use of laboratory animals. All animal experiments were approved by the experimental animal ethics committee at the Kumamoto University (B 26-058). Influenza-induced ALI model mice were produced by intratracheal injection of influenza virus suspension diluted with $\mathrm{LB}$ medium at a dose of $1.5 \times \mathrm{LD}_{50}$ under anesthesia with chloral hydrate $(500 \mathrm{mg} / \mathrm{kg})$ on day 0 . Either Trx or HSA-Trx was (but not both) administered intravenously (3.5 nmol protein in $200 \mu \mathrm{l}$ saline/mouse) via the mice tail vein at 4 and 6 days after virus infection. Tamiful ${ }^{\circledR}$ was administrated intraperitoneally $(10 \mathrm{mg} / \mathrm{kg} /$ day, 2 times/day) for 4 days from 2 days after virus infection. The efficacy of therapeutic agents was evaluated with mice sacrificed at 8 days after virus infection. 


\section{ANALYSIS OF LUNG LAVAGE SAMPLES}

The mice were anesthetized with diethyl ether, the chests were opened, and blood was sampled for measurement of hydroperoxides (described below). BALF was collected by cannulating the trachea and lavaging the lung with $1 \mathrm{ml}$ of sterile PBS containing $50 \mathrm{U} / \mathrm{ml}$ heparin (two times). About $1.8 \mathrm{ml}$ of BALF was routinely recovered from each animal. The BALF was centrifuged at $4,100 \times g$ for $5 \mathrm{~min}$ at $4^{\circ} \mathrm{C}$ to separate the cells in the BALF from the liquid. Cells were suspended in $0.9 \% \mathrm{NaCl}$ and the resulting lysate was centrifuged again. From the recovered cells, the total cell number was counted using a hemocytometer. Cells were stained with Diff-Quick reagents, and the ratios of alveolar macrophages, neutrophils, and lymphocytes to total cells were determined. More than 200 cells were counted for each sample. The protein concentration in BALF was measured with the Protein Assay Coomassie Brilliant Blue solution with BSA as a standard. IFN- $\gamma$ levels in BALF were measured by ELISA, following the manufacturer's suggested protocol.

\section{HISTOLOGICAL EXAMINATION OF LUNG TISSUE}

For the histological analysis, the recovered lung tissues were fixed in 10\% neutral-buffered formalin (Wako, Osaka, Japan), embedded in paraffin (Sakura Finetek Japan, Tokyo, Japan) and sectioned at $4-\mu \mathrm{m}$ thickness. The lung sections were subjected to hematoxylin and eosin (HE) staining for morphologic analysis, and immunohistochemistry for inducible nitric oxide synthase (iNOS) (N-20) (Santa Cruz Biotechnology, cat\#: sc-651, Santa Cruz, CA, USA), 8hydroxy-2'-deoxygenase (8-OHdG) (15A3) (Santa Cruz Biotechnology, cat\#: sc-66036, Santa Cruz, CA, USA), or 3-nitrotyrosine $\left(\mathrm{NO}_{2}\right.$-Tyr) (Millipore, cat\#: AB5411, Billerica, MA, USA). For the immunohistochemistry of iNOS, $8-\mathrm{OHdG}$, or $\mathrm{NO}_{2}$-Tyr, antigen retrieval was first performed by means of HistoVT One. A solution containing $50 \mathrm{mM}$ Tris- $\mathrm{HCl}$ (pH 7.4) and 0.1\% Tween-20 (T-TB) was then used to solubilize the hepatic slices, followed by blocking with Block Ace (Dainippon Pharmaceutical, Osaka, Japan) at $25^{\circ} \mathrm{C}$ for $15 \mathrm{~min}$. Next, reaction with the primary antibody was carried out overnight at a temperature below $4^{\circ} \mathrm{C}$. In addition, the primary antibodies against iNOS, $8-\mathrm{OHdG}$, or $\mathrm{NO}_{2}$-Tyr were diluted (1:50) with $0.5 \%$ BSA in PBS before use and conjugated with DAPI solution $(10 \mu \mathrm{g} / \mathrm{ml})$. The hepatic slices were then washed

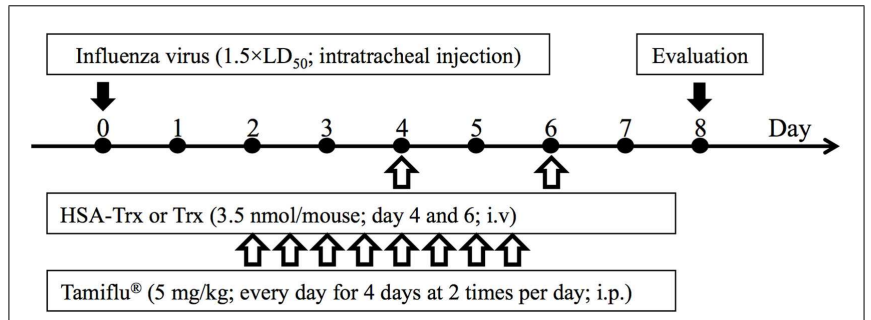

FIGURE 1 | Experimental protocol for the effective evaluation of HSA-Trx, Trx, or Tamiflu ${ }^{\circledR}$ on influenza-induced ALI model mice. Either HSA-Trx or Trx was administrated intravenously $(1.75 \mathrm{nmol} /$ mouse $)$ at 4 and 6 days after virus infection. Tamiflu ${ }^{\circledR}$ was administrated intraperitoneally ( $10 \mathrm{mg} / \mathrm{kg} /$ day, 2 times/day) for a total of 4 days, starting 2 days after the virus infection. The efficacy of therapeutic agents was evaluated with mice sacrificed at 8 days after virus infection. with $\mathrm{T}-\mathrm{TB}$, followed by reaction with the secondary antibody at $25^{\circ} \mathrm{C}$ for $1.5 \mathrm{~h}$. For iNOS and $\mathrm{NO}_{2}$-Tyr immunostaining, Alexa Fluor 488 goat anti-rabbit IgG $(\mathrm{H}+\mathrm{L})$ (Invitrogen, cat\#: A-11034, Tokyo, Japan) and for 8-OHdG immunostaining, Alexa Fluor 555 goat anti-mouse IgG $(\mathrm{H}+\mathrm{L})$ (Invitrogen, cat\#: A-21424, Tokyo, Japan) were diluted (1:200) with $0.5 \%$ BSA in PBS before use. After the reaction, the slide was observed under a microscope (Keyence, BZ-8000, Osaka, Japan). Image analyses of the extent and intensity of iNOS, 8 -OHdG and $\mathrm{NO}_{2}$-Tyr immunostaining were also performed using the image J software.

\section{MEASUREMENT OF PLASMA HYDROPEROXIDES}

Plasma was prepared from recovered blood sample. The plasma concentration of hydroperoxides (whole oxidant capacity of plasma against $\mathrm{N}, \mathrm{N}$-diethylparaphenylene-diamine in acidic buffer) was measured using the FREE carpe diem (Diacron International, Grosseto, Italy) following the manufacturer's recommended protocols. The measurement unit was CARR U. It has been established that 1 CARR U corresponds to $0.08 \mathrm{mg} / \mathrm{dl}$ hydrogen peroxide.

\section{MEASUREMENT OF VIRUS LOAD IN LUNG TISSUE}

The left lungs from influenza virus-infected mice were removed, weighed, and homogenized in $1 \mathrm{ml}$ of RPMI medium 1640. After centrifugation at $100 \times g$ for $10 \mathrm{~min}$ at $4^{\circ} \mathrm{C}$, the supernatant was

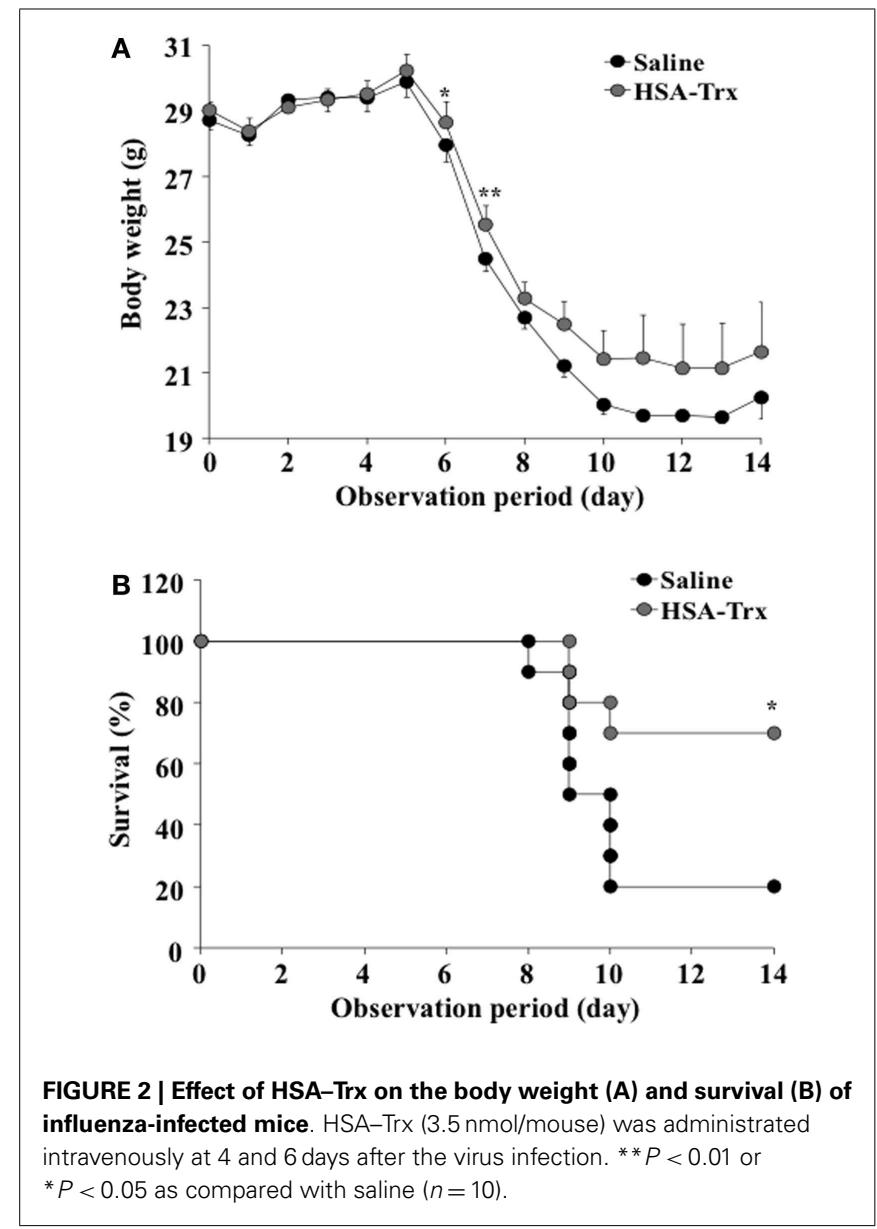


recovered. Virus titers were determined by a plaque assay on Madin-Darby canine kidney (MDCK) cells. MDCK cells were seeded on a 24 well culture plate and cultured until reaching confluency. Cells were washed with PBS, and then $0.1-\mathrm{ml}$ amounts of each dilution were inoculated to cultured cell followed by incubation for $1 \mathrm{~h}$ at $34^{\circ} \mathrm{C}$. DMEM $(0.5 \mathrm{ml})$ containing $100 \mathrm{U} / \mathrm{ml}$ penicillin, $100 \mu \mathrm{g} / \mathrm{ml}$ streptomycin, and $0.5 \mu \mathrm{g} / \mathrm{ml}$ fungizone was added to each well and incubated at $37^{\circ} \mathrm{C}$ for 3 days in a humidified incubator with $5 \% \mathrm{CO}_{2}$. Cytopathological effect was calculated and 50\% tissue culture infectious dose (TCID50) was calculated using the formula developed by Reed and Muench (20).

\section{PREPARATION OF FLUORESCEIN ISOTHIOCIANATE-LABELED HSA-TrX AND EVALUATION OF DISTRIBUTION TO BALF OF FITC-LABELED HSA-Trx IN INFLUENZA-INFECTED MICE}

Human serum albumin-Trx was labeled with fluorescein isothiocianate (FITC). HSA-Trx ( $4 \mathrm{mg} / \mathrm{ml})$ and FITC $(1 \mathrm{mg} / \mathrm{ml})$ were dissolved in $0.15 \mathrm{M} \mathrm{K}_{2} \mathrm{HPO}_{4}$ ( $\mathrm{pH} 9.5$ ), followed by mixing for $4 \mathrm{~h}$ at room temperature. The resulting solution was desalted by passage through a PD-10 desalting column and eluent was concentrated by Vivapore (Sartorius Stedim Biotech, A.S., France). FITC-labeled HSA-Trx $(3.5 \mathrm{nmol} /$ mouse $)$ was administrated intravenously to normal mice or model mice at 4 or 6 days after virus infection. At $2 \mathrm{~h}$ after its administration, the mice were anesthetized with diethyl ether, the chests were opened, and blood was drained. BALF was collected by cannulating the trachea and lavaging the lung with $1 \mathrm{ml}$ of sterile PBS containing $50 \mathrm{U} / \mathrm{ml}$ heparin. About $0.8 \mathrm{ml}$ of BALF was routinely recovered from each animal. The BALF was centrifuged at $4,100 \times g$ for $5 \mathrm{~min}$ at $4^{\circ} \mathrm{C}$ to separate the cells in the BALF from the liquid. The BALF levels of FITC-labeled HSA-Trx were quantified by using a spectral photometer (JASCO Corporation, MODEL: PTL-3965, Tokyo, Japan).

\section{STATISTICAL ANALYSIS}

All data are expressed as the mean \pm SE. Significant differences among each group were examined using a one-way of analysis of variance (ANOVA) followed by Bonferroni multiple comparison. A probability value of $P<0.05$ was considered to indicate statistical significance.

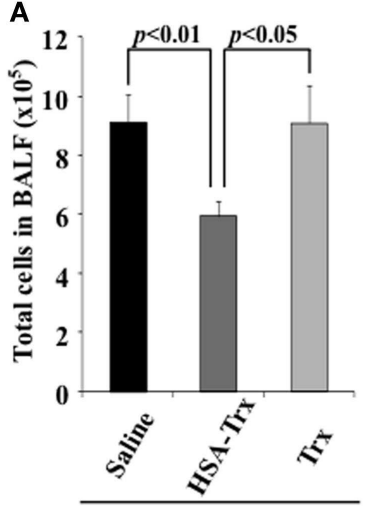

Influenza (+)
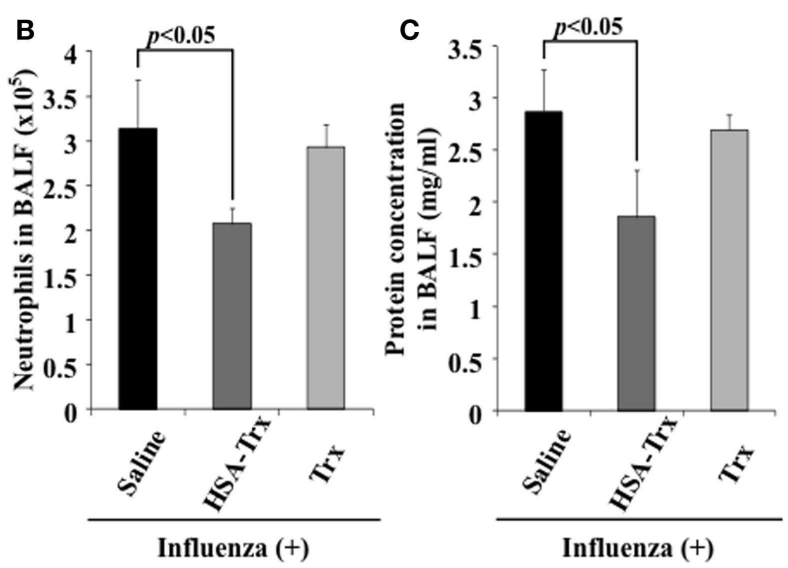

Influenza (+)

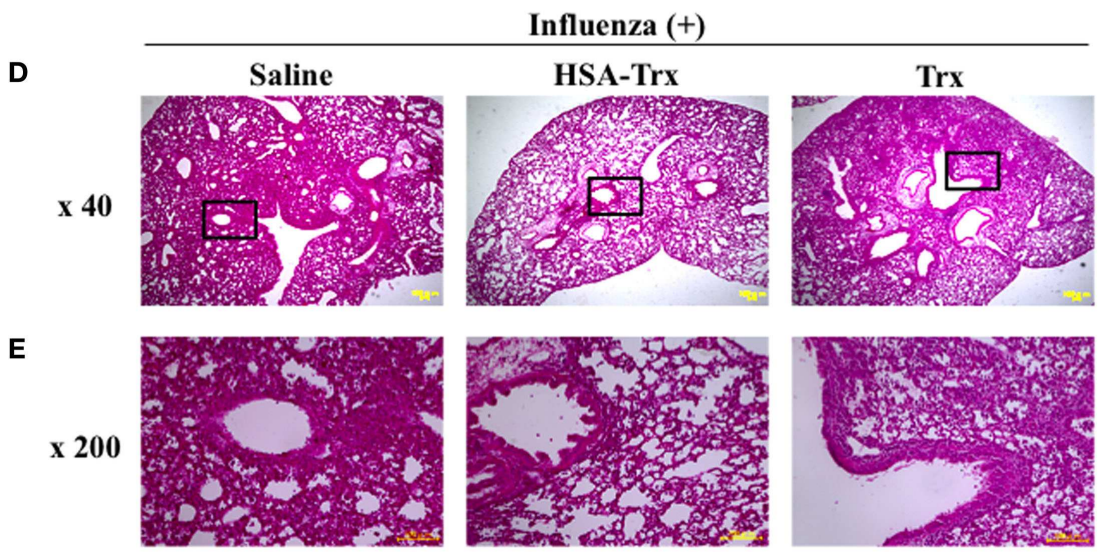

FIGURE 3 | Relative inhibitory effect of HSA-Trx or Trx on

influenza-infected mice. The same injected dose $(3.5 \mathrm{nmol} / \mathrm{mouse})$ of HSA-Trx or HSA was administered intravenously at 4 and 6 days after the virus infection. The numbers of (A) total cells and (B) neutrophils, or (C) protein concentration in BALF were determined at 8 days after virus infection. (D) Sections of pulmonary tissue were prepared at 8 days after virus infection, and subjected to histopathological examination (HE staining). Magnifications: $\times 40$ in (D); $\times 200$ in (E). Each value represents the mean \pm SE $(n=5)$. 


\section{RESULTS AND DISCUSSION \\ EFFECT OF HSA-Trx ON BODY WEIGHT AND SURVIVAL OF INFLUENZA-INFECTED MICE}

Acute lung injury was induced in mice by a single intratracheal administration of influenza virus at a dose of $1.5 \times \mathrm{LD}_{50}$ (day $0)$. Since Yashiro et al. reported that the multiple administration of $\operatorname{Trx}(3.5 \mathrm{nmol} /$ body) prevented influenza-induced ALI (15), we adopted a dose of HSA-Trx equivalent to one Trx treatment ( $3.5 \mathrm{nmol} /$ body). In Figure S1 in Supplementary Material, the time-dependent variation following the virus infection shows that the infiltration of inflammatory cells, especially neutrophils in BALF, lung edema, and injury was induced from day 4 to 6 after the initial virus infection. In addition, as shown in Figure S1D in Supplementary Material, the virus load after influenza infection reached a peak at day 4 , and then decreased. Therefore, HSA-Trx was injected at days 4 and 6 after the virus infection (Figure 1).

As shown in Figure 2, the body weight of the saline treated group mice decreased from day 6 after the virus infection, with $80 \%$ of them dead. On the other hand, HSA-Trx administration significantly suppressed the diminished body weight and increased the survival rate in virus-infected mice. Finally, 70\% of the HSA-Trx treated mice were still alive at 14 days after the virus infection.

\section{RELATIVE INHIBITORY EFFECT OF HSA-TrX OR Trx ON INFLUENZA-INFECTED MICE}

We compared HSA-Trx vs. Trx for their protective effect at the same administration schedule against influenza-induced ALI mice (Figure 1). The influenza infection caused a significant induction in the infiltration of inflammatory cells, especially neutrophils in the BALF of infected mice on day 8 (Supporting Figure in Supplementary Material). The number of total cells and neutrophils in the BALF remained significantly lower in HSA-Trx treated mice compared with saline or Trx treated mice (Figures 3A,B).

The extent of acute lung damage elicited by the influenza virus infection was assessed based on the increase in total protein in the BALF. We compared the levels of protein in the BALF from the saline, HSA-Trx, or Trx treated mice. As shown in Figure 3C, HSATrx significantly suppressed the elevation in the BALF protein that was induced by the influenza virus. The Trx treatment failed to
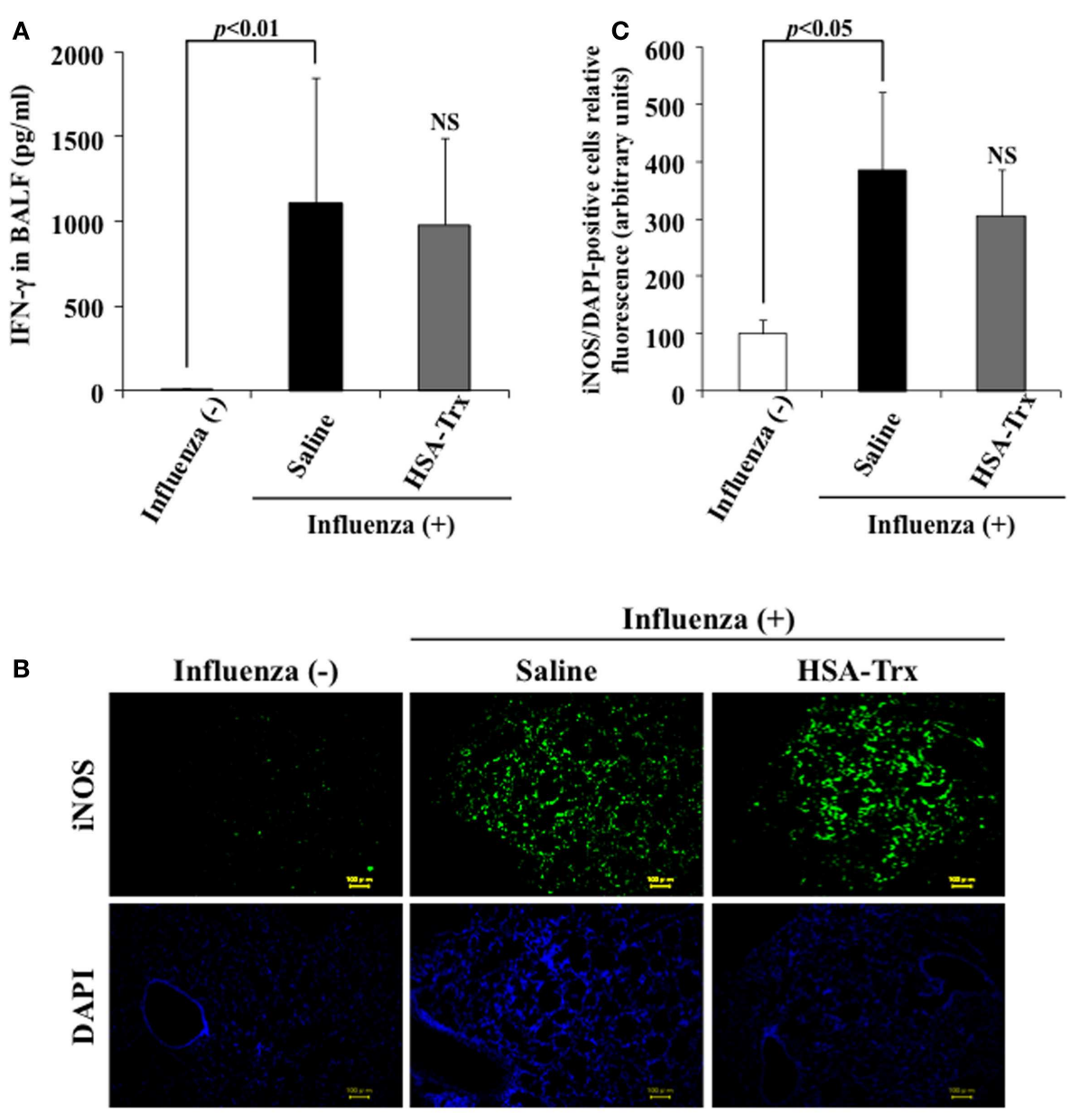

FIGURE 4 | Effect of HSA-Trx on BALF IFN- $\gamma$ and pulmonary iNOS expression in influenza-infected mice. (A) IFN- $\gamma$ levels in BALF were determined, and (B) immunostaining of lung slice for iNOS/DAPI was performed at 8 days after the influenza infection. (C) Image analysis of the extent and intensity of iNOS/DAPI staining was performed. Each bar represents the mean \pm SE [(A) $n=5$, (C) $n=4]$. NS; non-significant vs. saline. 
result in a significant reduction in the virus-induced elevation of protein concentration in the BALF (Figure 3C).

Hematoxylin and eosin staining of lung sections indicated that the virus-inoculated mice presented diffuse edema and inflammatory infiltration in the alveoli and interstitium of the lung, hemorrhaging, and thickened airways on day 8 (Supporting Figure in Supplementary Material). However, in lung sections from the HSA-Trx administration group, the extent of damage was attenuated, compared with the saline treated group. Histopathological findings for lung sections from the Trx administration group were similar to that for the saline administration group (Figures 3D,E). This tendency was similar to the previous findings for OVA or BLM-induced lung injuries, in that HSA-Trx ameliorated these lung injuries in an administration schedule in which Trx failed to show any efficacy against these injuries $(21,22)$. Therefore, the suppressive effect of HSA-Trx may be due to the extended retention of the fusion protein in the blood, compared to HSA via FcRn.
A

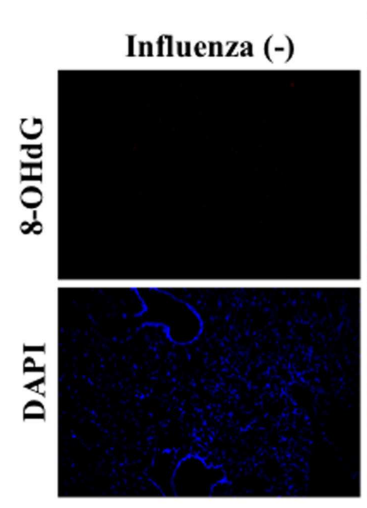

B
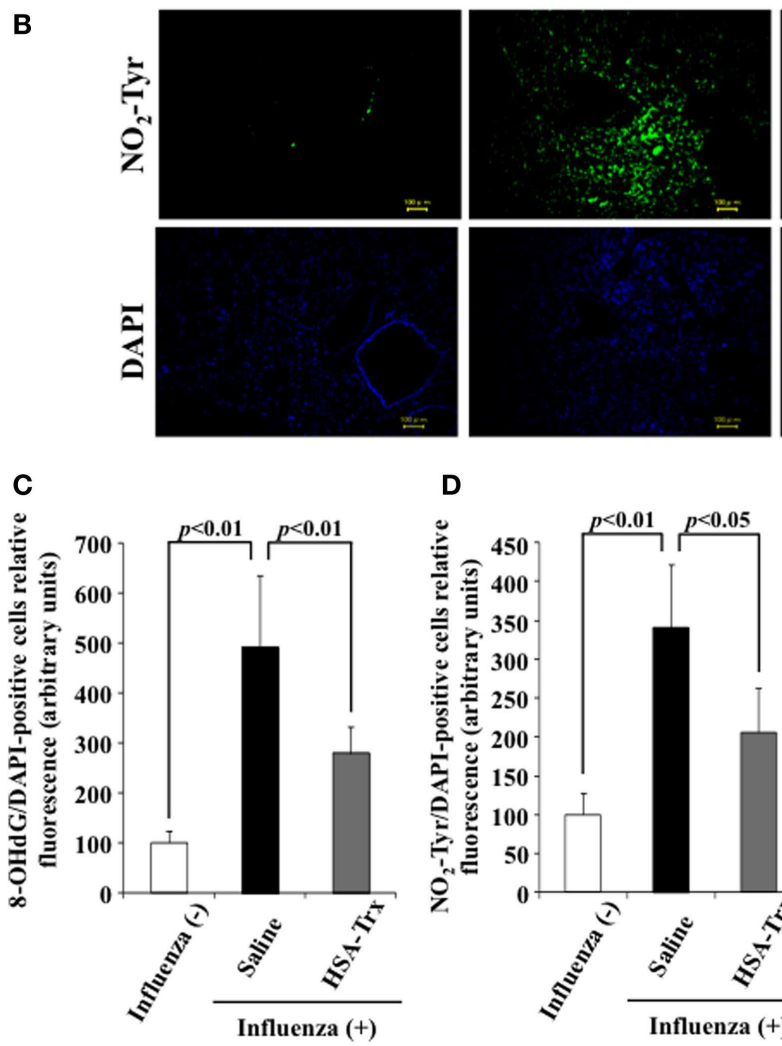

D

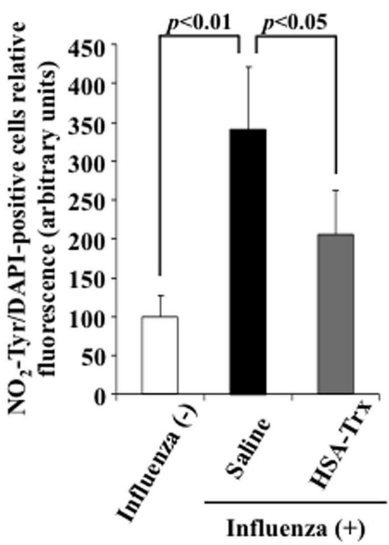

HSA-Trx
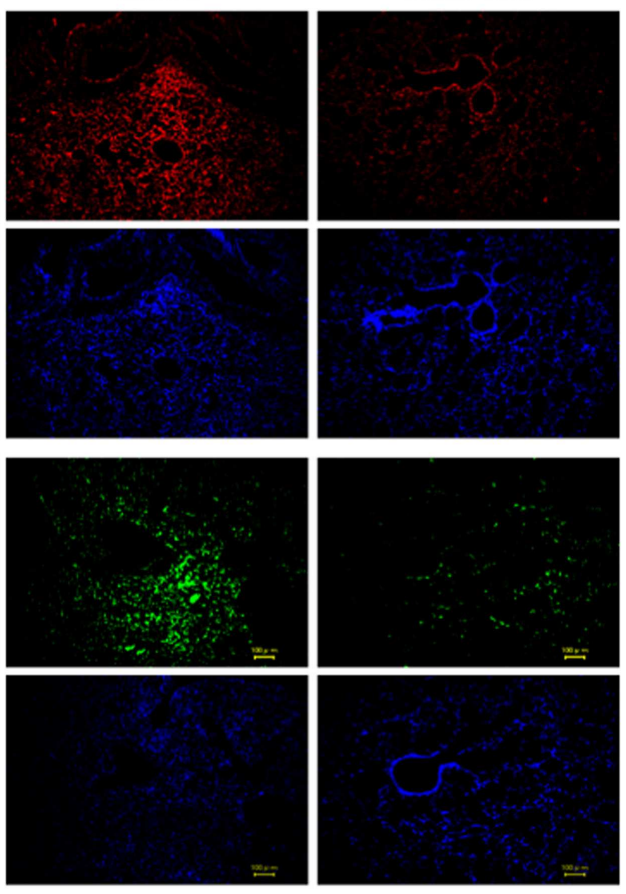

E

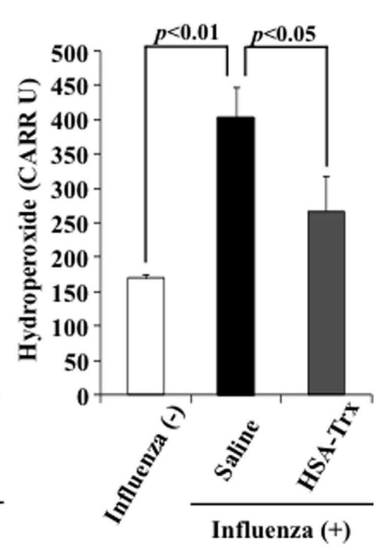

FIGURE 5 | Effect of HSA-Trx on pulmonary and plasma oxidative stress in influenza-infected mice. Immunostaining of lung slice for (A) 8-OHdG/DAPI and (B) $\mathrm{NO}_{2}$-Tyr/DAPI was performed at 8 days after the influenza infection. Image analysis of the extent and intensity of (C) 8-OHdG/DAPI and (D) $\mathrm{NO}_{2}$-Tyr/DAPI staining was performed. (E) Plasma hydroperoxide level was determined at 8 days after influenza infection. Each bar represents the mean \pm SE $(n=4)$. 


\section{EFFECT OF HSA-TrX ON BALF IFN- $\gamma$ AND PULMONARY iNOS EXPRESSION}

A previous report indicated that a large amount of IFN- $\gamma$ was induced in BALF obtained from influenza virus infections, and IFN- $\gamma$ up-regulated the expression of iNOS in alveolar macrophages, bronchial, and alveolar epithelial cells $(9,23)$. To reveal the mechanism underlying the suppressive effect of HSATrx on influenza-induced ALI, the levels of IFN- $\gamma$ in BALF or the expression of iNOS in lung tissue was confirmed by ELISA or immunostaining, respectively. As shown in Figure 4, the administration of HSA-Trx failed to reduce the increased levels of expressed IFN- $\gamma$ and iNOS that were produced as the result of a viral infection.

\section{EFFECT OF HSA-Trx ON OXIDATIVE STRESS IN LUNG TISSUE}

Previous reported findings suggest that ROS released from activated leukocytes, especially alveolar macrophages and neutrophils, are associated with the development of influenza-induced ALI (6). In fact, the genetic knockout of NADPH-oxidase in which neutrophils are produced, resulted in the suppression of influenzainduced ALI (24). In addition, NO released by iNOS reacts with $\mathrm{O}_{2}^{--}$derived from activated leukocytes to produce peroxynitrite $\left(\mathrm{ONOO}^{-}\right)$that has a strong injurious activity. $\mathrm{ONOO}^{-}$can nitrate a wide range of biological targets, such as proteins and fatty acids to produce $\mathrm{NO}_{2}$-Tyr adducts (25).

To evaluate the effect of HSA-Trx on the oxidative stress induced by a virus infection, lung tissue was immunostained
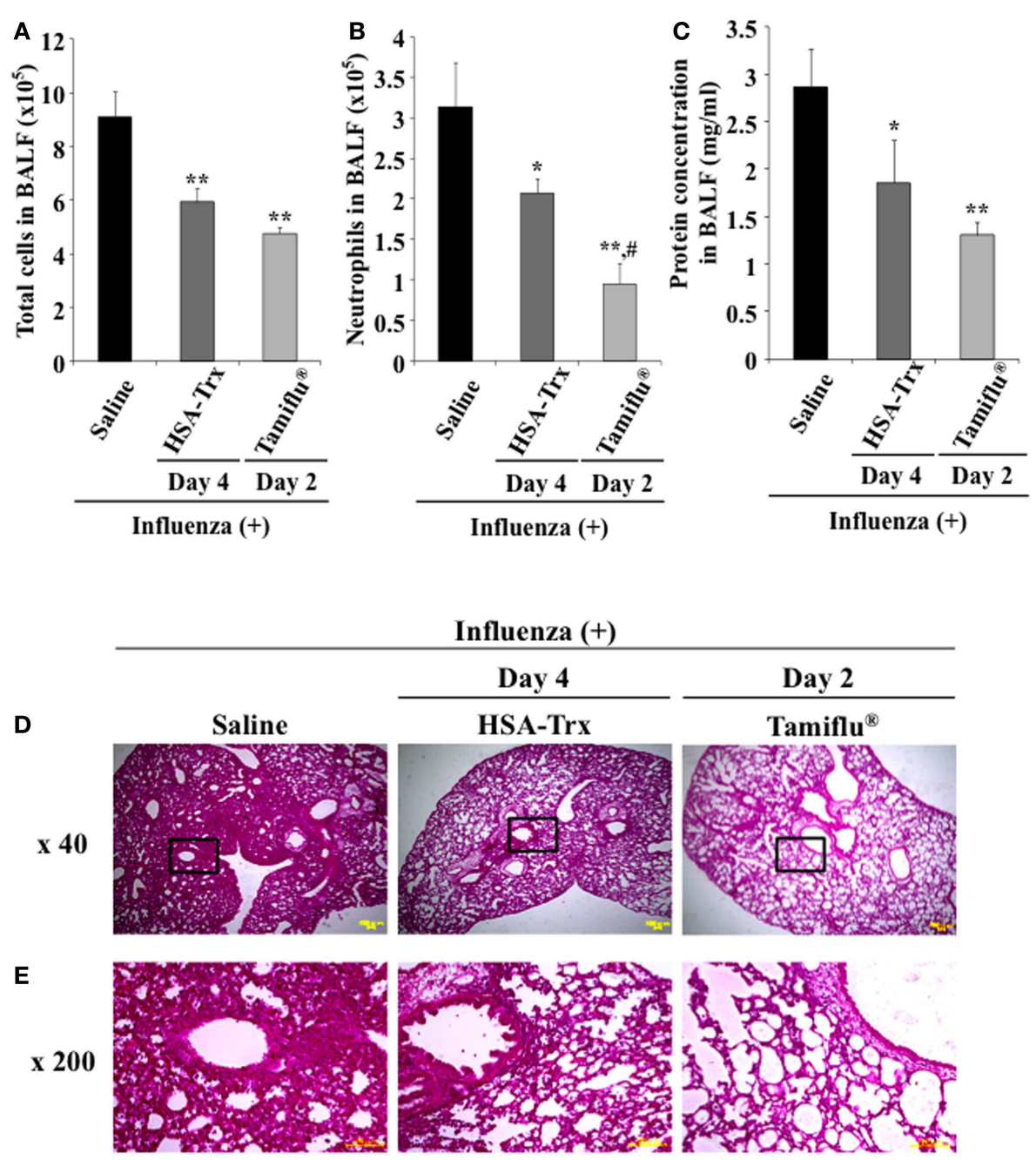

FIGURE 6 | Relative inhibitory effect of HSA-Trx or Tamiflu ${ }^{\circledR}$ on influenza-infected mice. HSA-Trx $(3.5 \mathrm{nmol} /$ mouse) was administered intravenously at 4 and 6 days after virus infection. Tamiflu ${ }^{\otimes}(5 \mathrm{mg} / \mathrm{kg})$ was administrated intraperitonealy every day at 2 times per day for a total of 4 days starting on 2 day after the influenza infection. The numbers of (A) total cells and (B) neutrophils, or (C) protein concentration in BALF were determined at 8 days after virus infection. (D) Sections of pulmonary tissue were prepared at 8 days after virus infection, and subjected to histopathological examination (HE staining). Magnifications: $\times 40$ in (D); $\times 200$ in (E). Each value represents the mean $\pm \operatorname{SE}(n=5)$. ${ }^{*} P<0.05$ and ${ }^{*} P<0.01$ as compared with saline. ${ }^{*} P<0.05$ as compared with HSA-Trx. 
for $8-\mathrm{OHdG}$ and $\mathrm{NO}_{2}$-Tyr, an oxidized product of nucleic acids and proteins, respectively, on day 8 after the influenza infection. Additionally, to determine the levels of hydroperoxide in plasma, dROMs tests were performed. As shown in Figure 5, the expression of 8-OHdG and $\mathrm{NO}_{2}$-Tyr in lung tissue and plasma hydroperoxides levels were increased in influenza-infected mice compared to normal mice, while HSA-Trx clearly suppressed the levels of these oxidative stress markers. Our previous report suggested that HSA-Trx has direct scavenging activities against $\left(\mathrm{O}_{2}^{--}\right)$derived from activated neutrophils and that this effect is concentration dependent (22). Therefore, the inhibitory effect of oxidized products that accumulated was thought to involve the same mechanism as proposed in a previous report. Furthermore, Trx has antichemotaxis properties for neutrophils by inhibiting the activation of p38 mitogen-activated protein kinase, the downregulation of L-selectin (CD62L) and adhesion to endothelial cells (13). In fact, as shown in Figure 3B, HSA-Trx significantly lowered the number of neutrophils in the BALF of influenza-infected mice. Taken together, the mechanism underlying the improving effect of HSA-Trx on influenza-induced ALI could be not only attributed exclusively to an anti-oxidative effect but also anti-chemotaxis appears to be involved.

\section{RELATIVE INHIBITORY EFFECT OF HSA-TrX OR TAMIFLU ${ }^{\circledR}$ ON INFLUENZA-INFECTED MICE}

For future clinical applications, the inhibitory effect of HSA-Trx against influenza-induced ALI was examined. A previous study demonstrated that the intraperitoneal administration of Tamiflu ${ }^{\circledR}$ $(5 \mathrm{mg} / \mathrm{kg})$ daily at two times per day showed a protective effect for influenza-induced ALI (26). Hence, the inhibitory effect of HSA-Trx ( $3.5 \mathrm{nmol} / \mathrm{mouse}$, i.v.) at 4 and 6 days against influenzainduced ALI was compared with that of Tamiflu ${ }^{\circledR}(5 \mathrm{mg} / \mathrm{kg})$, which was administered every day at 2 times per day for 4 days from 2 day after the influenza infection (Figure 1). The evaluation items were the same as Figure 3. As shown in Figure 6, Tami$\mathrm{flu}^{\circledR}$ also significantly suppressed the derivation of inflammation cells and neutrophils infiltration, protein elevation in BALF and lung histopathological alteration caused by the influenza virus. The suppressive effect of Tamiflu ${ }^{\circledR}$ treatment group was slightly stronger than that of HSA-Trx.

\section{EFFECT OF HSA-TrX OR TAMIFLU ${ }^{\circledR}$ ON VIRAL TITERS}

To validate that HSA-Trx treatment did not inhibit viral replication, we performed a plaque-forming assay in MDCK cells using the lung supernatant recovered from mice at day 4 or 6 after the virus infection. As shown in Figure 7, although the Tamiflu ${ }^{\circledR}$ treatment markedly inhibited virus proliferation, no significant difference between the lung viral titers in the Saline and HSATrx administration mice was found. These results indicate that HSA-Trx, unlike a Tamiflu ${ }^{\circledR}$, treatment ameliorates the acute lung damage induced by the virus infection without affecting viral propagation in the lungs of these mice.

\section{BALF DISTRIBUTION OF FITC-LABELED HSA-TrX IN INFLUENZA-INFECTED MICE}

The concentration of albumin in alveolar fluid is usually much lower than that in the blood, whereas the concentration can

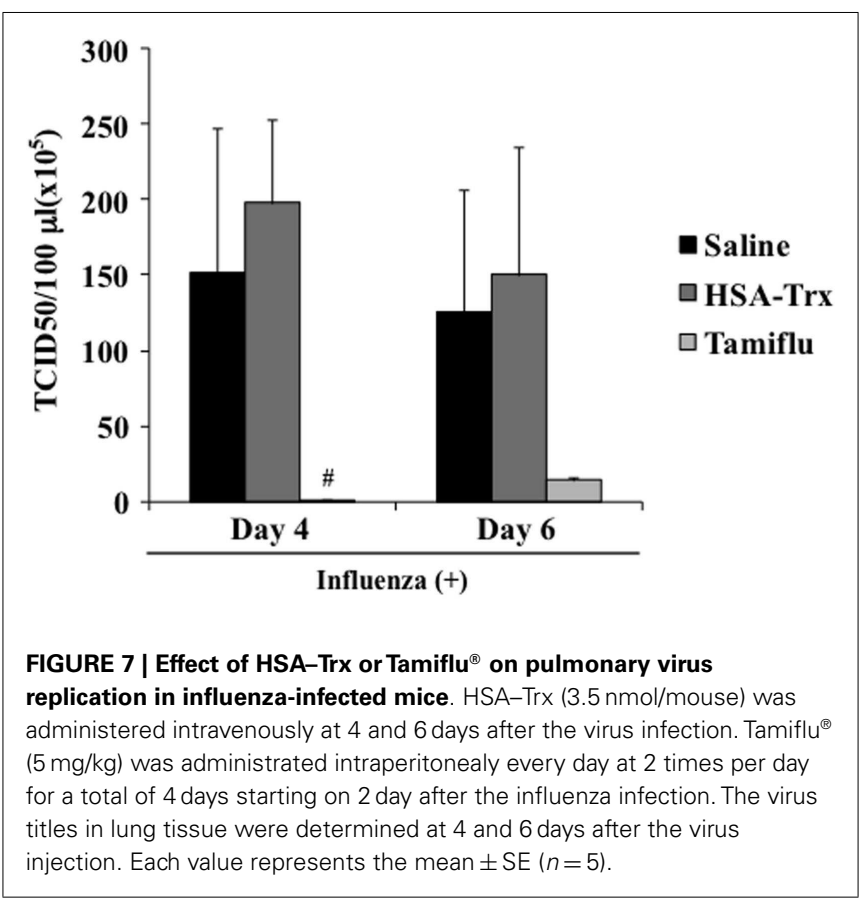

increase to $75-95 \%$ of the plasma level in the case of a lung injury due to vascular hyperpermeability caused by a marked elevation in the surfactant's surface tension (27). In fact, the albumin concentration in BALF is used as a bio-marker of lung injuries in clinical settings. Thus, it would be predicted that the BALF distribution of exogenous HSA-Trx in influenza-infected mice would be higher than that in influenza-non-infected mice. Hence, FITC-labeled HSA-Trx was prepared, and the distribution to BALF at $2 \mathrm{~h}$ after its administration in control mice (Day 0) or model mice on day 4 (Day 4) or 6 (Day 6) after the virus infection was evaluated. As shown in Figure 8, the BALF distribution of FITC-labeled HSATrx at Day 6 was approximately 4 times higher than that at Day 0. This result suggests that the distribution of HSA-Trx to the site of the lesion, the interstitium in influenza-infected patients may be higher than that in healthy subjects.

\section{CONCLUSION}

We evaluated the therapeutic effects of HSA-Trx, a long-lasting anti-oxidant and anti-inflammatory modulator that acts via the efficient receptor-mediated recycling pathway involving FcRn, on influenza-induced ALI model mice, and reached four major findings; (1) The post-administration of HSA-Trx suppressed influenza-induced ALI, (2) The mechanism by which HSA-Trx inhibited influenza-induced ALI can be attributed to a combination of anti-oxidative and anti-chemotaxis effects, (3) Unlike Tamiflu ${ }^{\circledR}$ the HSA-Trx treatment ameliorated acute lung damage induced by the virus infection without affecting viral propagation in the lung of these mice, (4) The distribution of HSA-Trx to the lesion site, namely the interstitium in influenza-infected patients may be higher than that in healthy subjects. Thus, we conclude that HSA-Trx has considerable potential for use as a therapeutic agent for the treatment of various acute inflammatory disorders such as influenza-virus-induced pneumonia. 


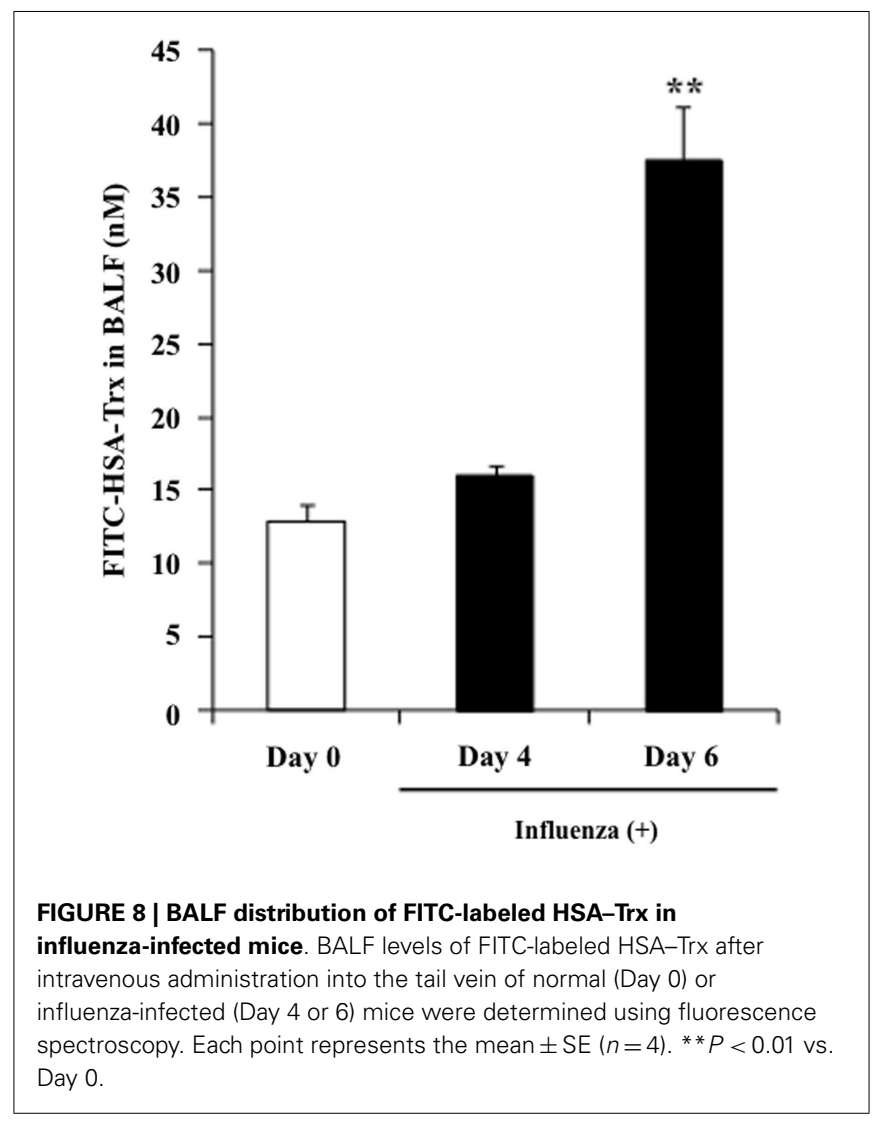

\section{ACKNOWLEDGMENTS}

We wish to thank the KAKETSUKEN for donating the Influenza virus [PR8 (H1N1)]. This work was supported in part by Grantsin-Aid from the Japan Society for the Promotion of Science (JSPS), a Grant-in-Aid from the Ministry of Education, Culture, Sports, Science, and Technology (23390142, 18390051 and 22790162), Japan. The work was also in part supported by grants from the Uehara Memorial Foundation and the Yasuda Medical Foundation and KUMAYAKU Alumni Research Fund.

\section{SUPPLEMENTARY MATERIAL}

The Supplementary Material for this article can be found online at http://www.frontiersin.org/Journal/10.3389/fimmu.2014.00561/ abstract

\section{REFERENCES}

1. Doherty PC, Turner SJ, Webby RG, Thomas PG. Influenza and the challenge for immunology. Nat Immunol (2006) 7:449-55. doi:10.1038/ni1343

2. Abdel-Ghafar AN, Chotpitayasunondh T, Gao Z, Hayden FG, Nguyen DH, de Jong MD, et al. Update on avian influenza A (H5N1) virus infection in humans. N Engl J Med (2008) 358:261-73. doi:10.1056/NEJMra0707279

3. Perez-Padilla R, de la Rosa-Zamboni D, Ponce de Leon S, Hernandez M, Quiñones-Falconi F, Bautista E, et al. Pneumonia and respiratory failure from swine-origin influenza A (H1N1) in Mexico. N Engl J Med (2009) 361:680-9. doi:10.1056/NEJMoa0904252

4. Moscona A. Neuraminidase inhibitors for influenza. N Engl J Med (2005) 353:1363-73. doi:10.1056/NEJMra050740

5. Moscona A. Oseltamivir resistance - disabling our influenza defenses. N Engl J Med (2005) 353:2633-6. doi:10.1056/NELMp058291
6. Vlahos R, Stambas J, Selemidis S. Suppressing production of reactive oxygen species (ROS) for influenza A virus therapy. Trends Pharmacol Sci (2012) 33:3-8. doi:10.1016/j.tips.2011.09.001

7. Akaike T, Ando M, Oda T, Doi T, Ijiri S, Araki S, et al. Dependence on O2generation by xanthine oxidase of pathogenesis of influenza virus infection in mice. J Clin Invest (1990) 85:739-45. doi:10.1172/JCI114499

8. Shi XL, Shi ZH, Huang H, Zhu HG, Zhou P, Ju D. Therapeutic effect of recombinant human catalase on $\mathrm{H} 1 \mathrm{~N} 1$ influenza-induced pneumonia in mice. Inflammation (2010) 33:166-72. doi:10.1007/s10753-009-9170-y

9. Akaike T, Noguchi Y, Ijiri S, Setoguchi K, Suga M, Zheng YM, et al. Pathogenesis of influenza virus-induced pneumonia: involvement of both nitric oxide and oxygen radicals. Proc Natl Acad Sci U S A (1996) 93:2448-53. doi:10.1073/pnas.93.6.2448

10. Suliman HB, Ryan LK, Bishop L, Folz RJ. Prevention of influenza-induced lung injury in mice overexpressing extracellular superoxide dismutase. Am J Physiol Lung Cell Mol Physiol (2001) 280:L69-78.

11. Hashiba T, Suzuki M, Nagashima Y, Suzuki S, Inoue S, Tsuburai T, et al. Adenovirus-mediated transfer of heme oxygenase-1 cDNA attenuates severe lung injury induced by the influenza virus in mice. Gene Ther (2001) 8:1499-507. doi:10.1038/sj.gt.3301540

12. Nakamura T, Nakamura H, Hoshino T, Ueda S, Wada H, Yodoi J. Redox regulation of lung inflammation by thioredoxin. Antioxid Redox Signal (2005) 7:60-71. doi:10.1089/ars.2005.7.60

13. Nakamura H, Herzenberg LA, Bai J, Araya S, Kondo N, Nishinaka Y, et al. Circulating thioredoxin suppresses lipopolysaccharide-induced neutrophil chemotaxis. Proc Natl Acad Sci U S A (2001) 98:15143-8. doi:10.1073/pnas. 191498798

14. Ueda S, Nakamura T, Yamada A, Teratani A, Matsui N, Furukawa S, et al. Recombinant human thioredoxin suppresses lipopolysaccharide-induced bronchoalveolar neutrophil infiltration in rat. Life Sci (2006) 79:1170-7. doi:10.1016/j.lfs. 2006.03.026

15. Yashiro M, Tsukahara H, Matsukawa A, Yamada M, Fujii Y, Nagaoka Y, et al. Redox-active protein thioredoxin-1 administration ameliorates influenza A virus (H1N1)-induced acute lung injury in mice. Crit Care Med (2013) 41:171-81. doi:10.1097/CCM.0b013e3182676352

16. Ikuta S, Chuang VT, Ishima Y, Nakajou K, Furukawa M, Watanabe H, et al. Albumin fusion of thioredoxin - the production and evaluation of its biological activity for potential therapeutic applications. J Control Release (2010) 147:17-23. doi:10.1016/j.jconrel.2010.05.020

17. Andersen JT, Pehrson R, Tolmachev V, Daba MB, Abrahmsén L, Ekblad C. Extending half-life by indirect targeting of the neonatal $\mathrm{Fc}$ receptor $(\mathrm{FcRn})$ using a minimal albumin binding domain. J Biol Chem (2011) 286:5234-41. doi:10.1074/jbc.M110.164848

18. Kodama A, Watanabe H, Tanaka R, Tanaka H, Chuang VT, Miyamoto Y, et al. Human serum albumin-thioredoxin fusion protein prevents experimental contrast-induced nephropathy. Kidney Int (2013) 83:446-54. doi:10.1038/ki. 2012.429

19. Tanaka R, Ishima Y, Maeda H, Kodama A, Nagao S, Watanabe H, et al. Albumin fusion prolongs the antioxidant and anti-inflammatory activities of thioredoxin in mice with acetaminophen-induced hepatitis. Mol Pharm (2014) 11:1228-38. doi:10.1021/mp400690v

20. Reed LJ, Muench H. A simple method of estimating fifty percent endpoints. Am J Hyg (1938) 27:493-7.

21. Furukawa M, Tanaka R, Chuang VT, Ishima Y, Taguchi K, Watanabe H, et al. Human serum albumin-thioredoxin fusion protein with long blood retention property is effective in suppressing lung injury. J Control Release (2011) 154:189-95. doi:10.1016/j.jconrel.2011.05.013

22. Tanaka R, Watanabe H, Kodama A, Chuang VT, Ishima Y, Hamasaki K, et al. Long-acting human serum albumin-thioredoxin fusion protein suppresses bleomycin-induced pulmonary fibrosis progression. J Pharmacol Exp Ther (2013) 345:271-83. doi:10.1124/jpet.112.201814

23. Hibbs JB, Taintor RR, Vavrin Z. Macrophage cytotoxicity: role for L-arginine deiminase and imino nitrogen oxidation to nitrite. Science (1987) 235:473-6. doi:10.1126/science. 2432665

24. Vlahos R, Stambas J, Bozinovski S, Broughton BR, Drummond GR, Selemidis S. Inhibition of Nox2 oxidase activity ameliorates influenza A virus-induced lung inflammation. PLoS Pathog (2011) 7:e1001271. doi:10.1371/journal.ppat. 1001271 
25. Pryor WA, Squadrito GL. The chemistry of peroxynitrite: a product from the reaction of nitric oxide with superoxide. Am J Physiol (1995) 268: L699-722.

26. Sidwell RW, Huffman JH, Barnard DL, Bailey KW, Wong MH, Morrison A, et al. Inhibition of influenza virus infections in mice by GS4104, an orally effective influenza virus neuraminidase inhibitor. Antiviral Res (1998) 37:107-20. doi:10.1016/S0166-3542(97)00065-X

27. Hastings RH, Folkesson HG, Matthay MA. Mechanisms of alveolar protein clearance in the intact lung. Am J Physiol Lung Cell Mol Physiol (2004) 286:L679-89. doi:10.1152/ajplung.00205.2003

Conflict of Interest Statement: The authors declare that the research was conducted in the absence of any commercial or financial relationships that could be construed as a potential conflict of interest.
Received: 01 September 2014; accepted: 21 October 2014; published online: 05 November 2014.

Citation: Tanaka R, Ishima Y, Enoki Y, Kimachi K, Shirai T, Watanabe H, Chuang VTG, Maruyama $T$ and Otagiri $M$ (2014) Therapeutic impact of human serum albumin-thioredoxin fusion protein on influenza virus-induced lung injury mice. Front. Immunol. 5:561. doi: 10.3389/fimmu.2014.00561

This article was submitted to Immunotherapies and Vaccines, a section of the journal Frontiers in Immunology.

Copyright (C) 2014 Tanaka, Ishima, Enoki, Kimachi, Shirai, Watanabe, Chuang, Maruyama and Otagiri. This is an open-access article distributed under the terms of the Creative Commons Attribution License (CC BY). The use, distribution or reproduction in other forums is permitted, provided the original author(s) or licensor are credited and that the original publication in this journal is cited, in accordance with accepted academic practice. No use, distribution or reproduction is permitted which does not comply with these terms. 